\title{
Exploration and Practice of Higher Vocational Typesetting Course Teaching Reform
}

\author{
Fan Lijuan* \\ Liaoning Mechatronics College \\ Dandong Liaoning, China \\ e-mail: arnold0110@sina.com \\ * Corresponding Author
}

\begin{abstract}
Typesetting course is a core course in higher vocational printing graphics and text information processing major; the course must adapt to the demands of era development and major construction, and enhancing the exploration and the practice of the course teaching reform is especially important. This paper will proceed from teaching practice, combine course characteristics and clear the course construction thinking, and focuses on strengthening construction work of course teaching contents, organization of course construction, and teaching model innovations, strengthening the professional standards and the post consciousness of students, and continuously improving the integrative competence of the students.
\end{abstract}

Keywords-Higher vocational education;typesetting; course construction; teaching reform; practice

Fund project-Study and Practice of fusion of printing professional skill competition and conventional teaching of Liaoning Mechatronics College
number:JYLX2015034)

The higher vocational education aims at training advanced technology application and production service personnel. In the teaching process of the students, the practical abilities of the students should be stressed continuously, and typical working cases should be selected to foster the professional consciousness, the professional emotion, the professional ethics and the professional skill of the students in a real working situation. In this paper, the construction contents and practice of the typesetting course will be introduced with the purpose of exploring the mode of the course teaching reform, making a course teaching summary and exchanging course construction experiences.

\section{SETTING CLEAR OBJECTIVE OF COURSE CONSTRUCTION}

The typesetting course is a core course in higher vocational printing graphics and text information processing major, and is a compulsory course for getting professional certificates of Founder electronic publishing and editing designers, typographers and maker-up. The teaching contents of the course are set according to the professional competencies of the occupation field of newspaper job, journal job, graphic Ad design job and leaflet job that professional designers, electronic maker-up and Founder electronic typographers engage for a long term. Through the teaching of the course, the students are clear about the basic knowledge and the basic thinking of electronic typesetting operation, and are capable of getting through material collection, material treatment, layout, editing and typesetting of journal, newspaper, graphic Ad design, etc. On the basis of being proficient in operating Founder fit software, the students are capable of mastering the basic knowledge of publishing and the basic skill of the work flow operation of newspaper offices and publishing house, thus grasping creative layout of newspaper and books, and having the basic competence of analyzing and solving actual business problems.

\section{CLARIFYING COURSE CONSTRUCTION CONCEPT AND THINKING}

In this course, from the training requirement of highskilled talents, the core idea of course construction is to design teaching situations on the basis of the working process and construct a project-oriented and task-driven teaching system by taking the working process of real tasks as the carrier. From the post professional competence of electronic typesetting, the core idea of course construction is to construct the teaching contents of enterprise working process-based typical tasks, and the characteristic of combination of learning with working, professionalism, practicality and openness are fully embodied.

Professionalism is embodied in the following aspects: by taking "combination of learning with working" as the principle, according to the competency requirements on printing \& typesetting production posts, the members of the course construction groups positively cooperate with industry and enterprises to comprehensively clarify the working tasks and the working processes of corresponding professional posts and determine typical working tasks; through analysis on the typical working tasks, the typical working tasks are integrated according to the competency complexity to form the field of relative integrative competence; in the light of the requirements of working posts on knowledge, competence and quality, the teaching contents are selected by referring to the professional qualification standards of printing maker-up, plate-making workers and the like; by taking the real typical working tasks as the carrier, a learning situation is designed by combining with actual conditions and following cognitive rules and the law of professional development; by taking the printing \& typesetting production working process as the main line, by following action-oriented teaching concept of "teach-learn-do amalgamation" and taking the students as main parts, full-time teachers and part-time teachers organize and implement teaching together.

Practicality is embodied in the following aspects: in the teaching process, we group the students through a virtual working environment, and appoint "group leaders" 
and "members" in the groups. After tasks are explained and assigned, the "members" split up, and finally, all members in the groups collectively appraise works of the "members"; the "group leaders" and a faculty adviser decide the final scores; moreover, the score of each group is rated in the class, thereby enhancing the collective honor and the teamwork abilities of the students.

Openness is embodied in the following aspects: (1) openness of course contents selection: the real working tasks of the enterprises are processed and handled so as to adapt to the requirement of teaching; (2) openness of teaching modes: teaching is carried out by means of classroom instruction and practice and training base guidance and in a manner that the students are led to undertake enterprise projects, and teachers proceed counseling through internet forums, message pads, networking communication software (QQ) and the like; (3) openness of students' score evaluation: students' scores are evaluated in several ways of student self-evaluation, group evaluation, teacher evaluation, enterprise evaluation, etc.

\section{REASONABLY ARRANGING COURSE DESIGN STEPS}

By taking professional and innovative ability training as the core, start with professional post analysis, course planning design is performed, thus determining course contents, organizing and implementing teaching, exploring teaching means and making teaching method innovations, and moreover, test contents in line with professional skill qualification evaluation system are established. Around course connotations, we set about to implement course construction in five aspects.

Step1_ Constructing the target system of course teaching by taking professional ability training as the core. Through research and by organizing experts for discussion, analyzing the professional post ability so as to determine an operable course standard which is required by professional posts (groups), is specific in contents and can be evaluated.

Step2_ Designing a course teaching implementation plan by taking the professional practice activity rule of the practical work as the main line; through project guidance and modular teaching, integrating theory and practice teaching contents so as to strengthen comprehensive quality training.

Step3_ Organizing and implementing the teaching process by taking the students as the main parts, and designing several "fully-authentic" or "simulated" professional tasks to serve as learning projects so as to improve the comprehensive application special professional abilities of the students and adapt to the requirement of the professional environment; making the teaching means innovations, and integrating teaching, learning and doing so as to give full play to the subjective initiative of the students by applying multiple teaching methods.

Step4_ Organizing course design groups to carry out teaching process design according to the course standard and teaching resources; by adopting multiple teaching methods, such as project orientation-task drive, working task analysis, group discussion, role play and elicitation orientation, guiding the students to positively think and take delight in practice, thereby improving the effects of teaching and learning; according to the learning effects of the students, by combining with the information feedback, after the students go through real printing \& typesetting working experiences, of new requirements on course teaching, performing a new round of circulation of the five steps of professional post research, working task analysis, course content design, teaching resource development and teaching process design, thus embodying the requirement of openness, keeping course contents consistent with the enterprise demands and constantly meeting the learning needs of the students.

Step5_ By taking a course objective as the basis, establishing a course assessment mechanism linked with it.

\section{REINFORCING ORGANIZATION OF COURSE CONSTRUCTION}

Course is the most active factor of directly influencing talent training quality, and the level of the course construction directly relates to the teaching quality, while course is an important symbol of the level of running school, and embodies the comprehensive strength of a school. Through the course construction, the teaching quality is comprehensively promoted.

The course construction is a system project, and the course needs to be scientifically organized and managed. The organization of typesetting course construction mainly includes several aspects: planning and implementation of the course construction, construction of course groups and construction of a course construction technology platform.

1. Forming a leading working group of the typesetting course construction. The leading working group is mainly responsible for planning and checking the course, overall planning the implementation process of the construction and the organization of the course, and promoting the course construction through an effective motivation system.

2. Establishing course construction groups. Teachers are the key of the course construction; how to organize the teachers, arouse the positivity of the teachers, jointly give counsels to the course construction and participate in the overall process of the course construction is the primary task of the organization work of the course construction.

3. Building the course construction technology platform. The course is characterized in that high-quality normative, vivid, convenient and fast teaching and learning resources can be supplied, and a technology platform running smoothly is needed to support these resources. The contents of the typesetting course teaching platform contain course construction, theory teaching, practice teaching, learning evaluation, online exchange, references and the like, and the students can implement course learning through the campus network.

\section{SCIENTIFICALLY SELECTING COURSE TEACHING CONTENTS}

\section{A. Course teaching objective}

The course teaching objective is an expected effect of course learning. The typesetting course lays emphasis on the design capabilities and the design consciousness of the students and the ability training of pre-press operations; the teaching objective of the typesetting course is to train 
the students to not only have solid electronic typesetting theoretical knowledge but also have operating skill in the aspects of material collection, material treatment, layout, editing and typesetting of journal, newspaper, graphic Ad design, etc. from training professional abilities by taking the working analysis of professional post groups as the basis and applying abundant methods and advanced and scientific teaching means.

\section{B. Selection of teaching contents}

1) Proceeding course orientation class according to needs of professional posts

Through the teaching of the course, the students are clear about the basic knowledge and the basic thinking of electronic typesetting operation, and are capable of getting through material collection, material treatment, layout, editing and typesetting of journal, newspaper, graphic Ad design, etc. On the basis of being proficient in operating Founder fit software, the students are capable of mastering the basic knowledge of publishing and the basic skill of the work flow operation of newspaper offices and publishing house, thus grasping creative layout of newspaper and books, and having the basic competence of analyzing and solving actual business problems.

2) Breaking through a single classroom instructing method, and flexibly applying multiple teaching methods

In the teaching process, according to the working process, an action-oriented teaching model is adopted; by taking the students as the main parts of teaching, guidance is performed with specific tasks; by aiming at training abilities in all aspects of the students, theory and practice integrated teaching is implemented to make the students learn by doing.

In the specific units and tasks, because of different emphases of learning, we adopt multiple different teaching methods; in allusion to individual difference among the students, requirements of different levels are raised so as to realize individualized quality education.

3) Embodying competency-based and employmentoriented school-running thoughts, and designing teaching elaborately

For the classroom teaching process, each class mainly comprises a task clarifying link, a material collection link, a teacher demonstration link, a link that the student groups design works, a proofreading link, a link of making a proof, a link that part of the students show design achievements, an evaluation link and the like

Task clarification: when the class begins, the teacher makes the students know the tasks and the learning contents, which need to be finished, of that course through a clear task mode; moreover, the students are guided to determine design methods and means, which they should adopt to finish the practical tasks, and operation procedures and thoughts for realizing the practical tasks on the basis of enjoying excellent case works.

Teacher's guidance: in this process, the teacher firstly needs to demonstrate the work that has been designed on her/his own, and then, demonstrates and operates concrete typesetting design process according to the methods and the thoughts analyzed above. Then, the teacher proposes the requirement details of imitated design for the students.

Students' practice: the students analyze and allocate the design tasks in the groups according to the teacher's demonstration and the requirements of the practical tasks, and finally, realize the tasks.

Teaching evaluation: the teacher selects part of the groups for demonstration, or the students in the groups make demonstration by themselves; evaluation between the teacher and the students is carried out, and the score of this work is rated to serve as an evaluation process of the total score.

Task after class: the task after class refers to a stage design task that the students are organized into groups to finish a teaching carrier according to the schoolwork texts offered by the teacher by utilizing after-class time, and the task after class is handed to the course teacher; the course teacher organizes and selects part of the groups in due time to demonstrate the works, and the scores of the works are included in the examination score.

\section{Innovations of course teaching models}

1) Developing learning field course and training design capabilities and production participation abilities of students

In the development process of the course, it lays emphasis on training the design capabilities of the students; the learning situation refined from the working processes of the real typical working tasks is formed; teaching is implemented by adopting a task-based project teaching mode, and the learning process is guided in the form of "learning task list". The learning task list mainly has three actions: (1) guiding the students to learn the contents of the "learning task list"; (2) evaluating the learning effect in a manner of self-evaluation and mutual evaluation; (3) guiding the students to finish expansive learning beyond the learning tasks. In task-based teaching, the students are the main parts, and the full-time and parttime teacher with outstanding practical ability and vocational education teaching ability is a consultant, director and promoter of the learning process; the learning contents are derived from the real printing \& typesetting working tasks of the enterprises, and can embody the consistency between learning at school and practical working in the students.

2) Promoting talent training mode of combination of learning with working

In the teaching reform of the typesetting course, fusion of the theoretical knowledge and the practical skill and ability is enhanced by taking the specialized knowledge and the practical skill and ability required for related working posts during actual production. In the teaching process, around the employment-oriented school mission, a close link is established between school and the enterprises, the traditional classroom-centered talent training mode is reformed, and the talent training mode of combination of learning with working is vigorously promoted. Enterprise engineers are invited to jointly set the course contents, and participate in course development. Teaching and design exercises are performed by taking actual products, such as college newspaper editing, making of the enrollment guide, typesetting of college interior teaching materials, as cases. Teaching is performed in the enterprises, and the enterprise engineers are employed to guide and check the products designed by the students. The students are organized to go to the offcampus training base to visit and learn, so that the 
students can further know the practical working environment. School establishes the course standard together with the industry and the enterprises, and cooperates with the industry and the enterprises to develop the course. The talent training mode is more in favor of "seamless joint" between high vocational talent training and the enterprise demand.

3)Promoting project teaching mode by laying emphasis on task drive and taking project as orientation

In the teaching process, the teaching system of subject course is broken through; by adopting a task-driven and project-oriented teaching model, factors like working environments, working tasks and working processes of actual working posts after the students are employed are comprehensively considered. Implementing an "integration" teaching method of the combination of goal orientation and teaching task of the typesetting work with actual pre-press production, theory and practical training aims at focusing the working processes and working results and improving the training processes of highquality skill-oriented special talents.

4)Adopting "teach-learn-do" integrated course teaching model

The centralized "teach-learn-do" integrated course teaching model refers to reconstructing the course system and the teaching contents according to the vocational education rule, the characteristics of the course and the learning characteristics of high vocational students according to the knowledge and the capacity need of the course posts by taking typical application cases as the main line; the site of course learning is arranged in the training room and the production field, the teacher demonstrate while explaining, and the students ask questions while learning and practicing, thereby realizing the fusion of the knowledge and the skill.

5)Realizing process evaluation mode by taking working tasks as unit

The traditional student ability evaluation system is reformed, and the student ability development and the teacher teaching level are evaluated from multiple aspects of professional ability, method ability, social ability and the like by adopting a new student ability evaluation system combining forming process evaluation, summative authentication and comprehensive evaluation.

The evaluation method concretely implemented comprises the following steps that evaluation indexes are decomposed into all links of each working task; the students perform self-evaluation; then, the teacher gives formative evaluation on the performance conditions of the students in the process of executing the working tasks, gives summative evaluation on the performance of the students, and gives comprehensive quality evaluation on the teamwork spirit and the coordination abilities of the students in the process of executing the working tasks.

The course construction promotes the development in depth and breadth of the professional teaching reform, and is an updated educational concept. The key professional abilities of the students get promoted and get intensified training, and meanwhile, graduates can also be widely accepted by the enterprises.

\section{REFERENCES}

[1] Kang Lijuan, Application of Competency-based Project Teaching in "Business Etiquette" Course [J]. Education and Vocation. 2012(32): P152-P153.

[2] Ye Jianming, Liang Ningsen, Study on dynamic mechanism of integration of schools and enterprises of higher vocational education [J]. Vocational \& Technical Education Forum 2014(08):P16-P22,26.

[3] Shi Lihong, Zhu Dewen, Construction of Vocational Education Project-specific Course Situated Teaching Organization [J]. Vocational \& Technical Education Forum. 2011(06):P59-P62.

[4] Wang xiang, Vocational education "project-specific" teaching model building path and practice effect study $[\mathrm{J}]$. China Adult Education. 2014(11):P119-P122.

[5] Wang wei, Exploration of "project-oriented" course development in interior design major of higher vocational colleges [J]. Education and Vocation. 2010(15): P108-P109.

[6] Shen Guoliang, Exploration of existing problems in project teaching course development $[\mathrm{J}]$. China Adult Education. 2010(11):P159-P 160.

[7] F. C. Liu, X. Y. Chen, X. M. Mou, G. L. Li, L. Wang, "The Teaching Reform of Electric Engineering Course for the Excellent Plan", Journal of Electrical \& Electronic Education. Vol.33, Oct. 2011, pp.10-12.

[8] H. Y. Zhang, Y. G. Sun, "The Exploration of the Teaching Reform of Electric Engineering Course based on the Excellent Plan", China Electric Power Education, Jun. 2014, pp.62,85.

[9] S. R. Hu, H. Zhao, "Practice and Exploration of the Certification of Engineering Education in Electronic Information Engineering specialty", Journal of Wuhan University, Vol.2, Aug. 2012, pp.130-132.

[10] X. Z. Zhe, A. W. Han, "The Present Situation, problems, and countermeasures of Higher Engineering Education in China", Shanghai Journal of Educational Evaluation, Apr. 2015, pp.21-26. 